\title{
Vida Saludable: ¿Esta en Riesgo de Deshidratación? ${ }^{1}$
}

Jennifer Hillan ${ }^{2}$

Los adultos mayores están en mayor riesgo de deshidratación.

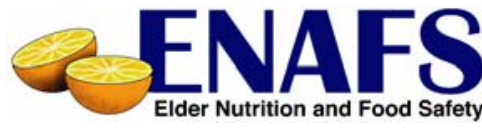

Hay muchas razones por las cuales usted podría estar en riesgo-algunas de estas podrían ser controladas pero otras no. Dése cuenta si usted esta en riesgo, y si lo esta, ¡vea como lo puede disminuir!

\begin{tabular}{|l|l|l|}
\hline & Si & NO \\
\hline Soy mayor de 85 años. & & \\
\hline Soy mujer. & & \\
\hline $\begin{array}{l}\text { Tengo diabetes, incontinencia urinaria, o problemas en } \\
\text { los riñones. }\end{array}$ & & \\
\hline Tengo fiebre frecuentemente, vomito, o diarrea. & & \\
\hline Tomo laxantes, diuréticos o sedantes. & & \\
\hline Tomo menos de 6 vasos de líquido cada día. & & \\
\hline Tengo orina amarilla oscura frecuentemente. & & \\
\hline Tengo problemas al tragar. & & \\
\hline
\end{tabular}

Si usted respondió "SI" a una de la oraciones anteriores, usted podría estar a un riesgo mas alto de deshidratación. Es importante prevenir la deshidratación, porque esto le puede traer serios problemas de salud y en algunos casos, hospitalización. Beba pequeñas cantidades de líquido cada día, así no tenga sed. Pruebe con agua normal o con sabor, jugos de frutas, sopas bajas en sodio, jugos de vegetales, bebidas deportivas diluidas y leche baja o sin grasa. El té y el café también lo pueden ayudar a

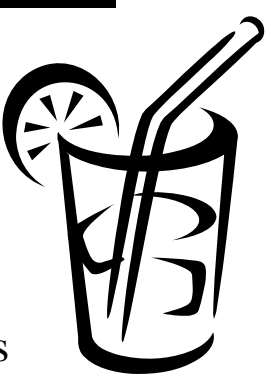
mantenerse hidratado.

1. The English version of this Spanish document is Healthy Living: Are You at Risk of Dehydration? (FCS8847). Este documento, FCS8847-SPAN, pertenece a una serie del Departamento de Ciencias de la Familia, Juventud y Comunidad, Servicio de Extensión Cooperativo de la Florida, Instituto de Alimentos y Ciencias Agrícolas, Universidad de la Florida. Fecha de publicación: junio 2007. Favor de visitar el sitio Web de EDIS en http://edis.ifas.ufl.edu.

2. Jennifer Hillan, MSH, RD, LD/N, ENAFS educadora nutricional, Departmento de Familia, Jovenes Y Ciencias Comunitarias, Servicio de Extencion de la Florida, Instituto de Alimentos y Ciencias Agrícolas, Universidad de la Florida, Gainesville, FL 32611. 